\title{
CDRI as an Instrument to Evaluate Infants With Developmental Problems Associated With Autism ${ }^{1}$
}

\author{
Nathalia Teixeira Caldas Campana ${ }^{2}$ \\ Universidade de São Paulo, \\ São Paulo-SP, Brazil
}

\author{
Rogério Lerner \\ Universidade de São Paulo, \\ São Paulo-SP, Brazil
}

\author{
Vinicius Frayze David \\ Universidade de São Paulo, \\ São Paulo-SP, Brazil
}

\begin{abstract}
This exploratory study investigates the contributions the Clinical Risk Indicators in Child Development (CDRI) may bring for the evaluation of infants who might be considered in autistic development. To do so, results of the evaluation - using CDRI and the Modified Checklist for Autism (M-CHAT) - of 43 babies who were 18 months old were compared. The present study showed that autism is amongst the risks the CDRI detects. The statistical analysis highlights that the axis Subject Assumption (SA) may not differentiate infants who present developmental problems associated with autism from typically developing ones. The Alternate Presence/Absence (PA) axis seems to be the one that most distinguishes these groups of infants. The clinical vignette demonstrates that CDRI can be used as a guide that helps to understand the family dynamics and can guide the interventions made in public health services.
\end{abstract}

Keywords: child development, autism, psychoanalysis, public health

\section{IRDI na Avaliação de Bebês com Problemas de Desenvolvimento Associados ao Autismo}

\begin{abstract}
Resumo: Esta pesquisa é um estudo exploratório com o objetivo de investigar contribuições que o protocolo Indicadores Clínicos de Risco para o Desenvolvimento Infantil (IRDI) pode trazer para avaliação de bebês que estejam se desenvolvendo em um percurso autístico. Para tanto, foram comparados resultados do IRDI e do Modified Checklist for Autism in Toddlers (M-CHAT) em 43 bebês de 18 meses de vida. O estudo demonstrou que dentre os riscos detectados pelo IRDI também está o autismo. A análise estatística aponta para a possibilidade de o eixo Suposição de Sujeito (SS) não diferenciar bebês com problemas de desenvolvimento associados ao autismo daqueles que apresentam um desenvolvimento típico. O eixo Alternância Presença/Ausência (PA) parece ser aquele que mais distingue os dois grupos de bebês. A vinheta clínica demonstra que o IRDI pode ser utilizado como um operador de leitura que auxilia a compreensão de dinâmicas familiares com potencial para orientar intervenções no contexto da saúde pública.
\end{abstract}

Palavras-chave: desenvolvimento infantil, autismo, psicanálise, saúde pública

\section{IRDI en la Evaluación de Bebés con Problemas de Desarrollo Asociados al Autismo}

Resumen: Esta investigacion es un estudio exploratorio con objeto de investigar contribuciones que el protocolo Indicadores Clínicos de Riesgo para el Desarrollo Infantil (IRDI) puede traer para evaluación de bebés que estén desarrollándose en un camino autístico. Para tanto, fueron comparados resultados del IRDI y del Modified Checklist for Autism in Toddlers (M-CHAT) en 43 bebés de 18 meses de vida. El estudio demostró que los riesgos detectados por el IRDI también incluyen está el autismo. El análisis estadístico indica la posibilidad de que el eje Suposición de Sujeto (SS) no diferencie bebés con problemas de desarrollo asociados al autismo de aquellos con desarrollo típico. El eje Alternancia Presencia/Ausencia (PA) parece ser el que más distingue los dos grupos de bebés. La viñeta clínica demuestra que el IRDI puede ser utilizado como un operador de lectura que auxilia la comprensión de dinámicas familiares con potencial para orientar intervenciones en el contexto de la salud pública.

Palabras clave: desarrollo infantil, autismo, psicoanálisis, salud pública

The investigation of early signs of developmental problems associated with autism is of interest to different researchers, given that clinical interventions during the

\footnotetext{
1 Paper taken from the first author's master's thesis under the second author's advice, defended in 2014 in the Graduate Program in School and Human Development Psychology at the University of São Paulo.

Support: The study received funding from the São Paulo Research Foundation - FAPESP (Protocol no. 2009/11840-4).

2 Correspondence address:

Nathalia Teixeira Caldas Campana. Av. Macuco, 726/1602. CEP 04523-001.

São Paulo-SP, Brazil. E-mail: nacampana@gmail.com
}

establishment of a symptom are more favorable to childhood development. In the public health context, professionals benefit from instruments that are easy to apply and do not require different protocols to detect specific disorders. Hence, the protocol called Clinical Indicators of Risk for Childhood Development, as it is not specific for diagnostic purposes, can be a feasible option. Therefore, the objective in this study is to investigate contributions of the CDRI protocol for the assessment of infants in autistic development. An exploratory study was developed on the association between 
the CDRI results and the results of risk for autism obtained on the Modified Checklist for Autism in Toddlers (M-CHAT) - a tool developed to identify children with signs of autism as from the age of 18 months, which is considered the gold standard in the scientific literature (Chlebowski, Robins, Barton, \& Fein, 2013; Pinto-Martin et al., 2008; Snow \& Lecavalier, 2008).

The notion of autism and its diagnostic criteria have undergone a series of modifications over time. Among the main characteristics of the so-called autism spectrum disorder (ASD) (American Psychiatric Association [APA], 2014), these children's social interaction and communication difficulties are highlighted, as well as restricted and repetitive patterns of behaviors, interests and activities. In view of the heterogeneous picture, however, some children present signs of autism since the first months of life, while others only do so after one year of life. In addition, the most common symptoms are not expressed similarly in children, despite some regularity that permits the construction of a diagnosis. From the neurodevelopmental perspective, ASD is considered a complex behavioral syndrome with multiple causes (Rutter, 2011) and the diagnostic construction of the disorder is based on each individual's behavior and developmental history (Zanon, Backes, \& Bosa, 2014). From the same perspective, Fernell, Eriksson and Gillberg (2013) affirm, based on neuroimaging studies, that the brain pathology underlying ASD is not located in a specific brain area, highlighting the prefrontal area, the brain stem and the cerebellum as generally affected regions.

In recent years, studies have indicated a significant increase in the number of cases diagnosed as autism in the general population. The recent indices of the Centers for Disease Control and Prevention [CDC] (2014) reveal the prevalence of one case in every 68 children. Possible reasons for this increase include new diagnostic criteria, the development of the broad autism spectrum concept, the different methods used in research on the theme, parents and professionals' greater perception and knowledge of the problem, the development of specialized services and the actual increase in the number of cases. Hence, ASD has increasingly concerned professionals and parents of young children and enhanced the debates in a wide range of knowledge areas.

In the USA and the European Union, research on autism in large samples has contributed to identify early signs of ASD (Eaves, Wingert, \& Ho, 2006; Pinto-Martin et al., 2008; Scarpa et al., 2013; Snow \& Lecavalier, 2008; Zanon et al., 2014). The tools used in those studies include the M-CHAT and Autism Diagnostic Interview - Revised (ADI-R) - protocols that assess the child's behavior through the parents' answers. Nevertheless, priority was granted to a method that did not consider the singularity of each subject/family assessed. Although the number of samples used did not permit the individual analysis of the interviewees, that fact was noteworthy that none of these studies associated quantitative analyses with qualitative data. This can revealed a detection trend that does not consider the subjectivity and can lead to the risk of merely alarming the parents and of capturing the child in a diagnostic forecast.

The Multicenter Research of Risk Indicators for Child Development was undertaken upon the request of the Brazilian Secretary of Health. This study validated a set of 31 clinical development indicators observed in the first 18 months of the infant's life. The absence of two or more indicators may be associated with developmental problems as well as mental risks in children at the age of three years (Kupfer et al., 2009).

The CDRI was elaborated for professional use in primary care services, based on the articulation between psychoanalysis and other fields. The construction of the tool rests on four axes around which the subjectivity is organized (Kupfer et al., 2009; Mariotto, 2009; Pesaro, 2010) and departs from the psychoanalytic concepts about the infants' emotional development and the relation established with their parents. The protocol's originality is exactly its assessment of the development based on the parents-infant interaction, given that most scales ignore the operators related to the subjectivation process.

1. Subject Assumption axis (SS): Refers to the caregiver's anticipation movements, that is, the possibility for the parents to attribute meaning to the infant's actions, supposing a subject in which subjectivity has not developed yet. This axis highlights the parents' role and value as operators of the infant's mental structures. Therefore, the indicators constructed based on this axis are focused on the parents.

2. Establishment of Demand axis (ED): Refers to the infant's first involuntary reactions (crying, motor agitation) the parents will recognize and interpret as a request directed at them. This axis evidences the infant's necessary alienation in early life. The indicators constructed based on this axis are directed at the caregivers as well as the infant.

3. Alternate Presence/Absence axis (PA): Refers to the actions of the caregiver who alternates between present and absent for the infant. In this context, the presence and absence are mainly symbolic. This axis is fundamental for the mental constitution, as the alternation permits the action of the maternal and paternal functions. It is important for the mother to gradually stop to immediately satisfy all of the infant's needs, as that will create room for the infant to develop the capacity to request and think. The indicators constructed based on this axis are focused on the caregiver as well as the infant.

4. Paternal Function axis (FP): Refers to the inclusion of a third person in the mother-infant relationship. The establishment of this function includes the child in the edipal problem and, therefore, introduces the infant into the field of interdiction and difference. This passage allows the child to establish itself as a subject of desire and culture. 
The presentation of the four axes reveals that these are articulated functions of the subjective process and refer to the constitution process of the subject, which is only possible in the infant's relation with the caregiver. Statistical analyses have indicated the CDRI's greater capacity to predict developmental problems than to predict mental risk (Kupfer et al., 2009, 2010; Lerner \& Kupfer, 2008). According to the authors, to find a disease like autism, whose incidence rate in the infant population is small, a larger sample would have been necessary.

Lerner (2011) investigated the discriminative properties of the CDRI for autism, mental delay and normality, applying the indicators to home videos of infants who turned into autistic children. According to the author, the CDRI demonstrates the power to distinguish among autism, mental delay and normality. Kupfer et al. (2013) suggest the preventive role of the CDRI in early childhood, which originated a work proposal called the CDRI method. In this context, the use of the tool would not be limited to the detection of signs of early suffering and the monitoring of mental development. Instead, it would serve as a reading operator to support the interventions. Lerner et al. (2013a, 2013b) evidenced that, even when used for assessment purposes, the CDRI can provide for interventions sensitive to each family's particularities. Campana and Lerner (2014) highlight that the application of the CDRI is promising to create an atmosphere of welcoming and listening for the families, guided by developmental aspects of the infants.

Based on the study objective, this proposal is justified by the need to investigate the potential of the CDRI protocol to detect babies showing autistic development. In addition, despite the existence of validated tools for this distinction, these are specific protocols to detect early signs of autism. Hence, the possible association between the results of the two tools (CDRI and M-CHAT) can contribute to consider the subjectivity in that context, furthering the understanding about autism based on psychoanalysis concepts presents on the four axes that originated the Indicators.

\section{Method}

\section{Participants}

The data were collected in 43 infants from different health institutions, only one of which was private. The remainder was part of public health services located in the city of São Paulo, Brazil. The criteria for the participants to be included in the sample universe were: infants between 0 and 18 months of age to whom the four ranges of the CDRI and the M-CHAT had been applied. In the total number of children the professionals from the institutions had indicated to participate in the study and who completed the assessment, there were 22 boys and 21 girls, all full-term infants. For statistical reasons, the collection was interrupted when a number was reached that permitted having at least 40 subjects in the outcome age of the assessment. As this was a longitudinal assessment, sample units were lost in the course of the process, as some children moved to another city and were attended at other health services. The parents' education level ranged from unfinished primary education to higher education and income ranges varies between two and ten minimum wages.

\section{Instruments}

Clinical Indicators of Risk for Child Development (CDRI). Applied in the course of the first 18 months of the infants' lives, given that the protocol is divided in four ranges (1st range: 0 to 4 months unfinished, 2 nd range: 4 to 8 months unfinished, 3rd range: 8 to 12 months unfinished and 4th range: 12 to 18 months) to be applied according to the child's age.

Modified Checklist for Autism in Toddlers (M-CHAT). Completed by the parents when the infant is 18 months old in the format of a checklist. The tool consists of 23 yes/no questions. The questions address themes related to the social relationship, joint attention, the fact of taking objects to show to the parents and the child's capacity to respond when called by another person. Each question corresponds to one point on a scale from zero to 23 . If the child scores more than three points on any of the items, (s)he is considered at risk of autism; in case of two points from critical items (questions 2, $7,9,13,14$ and 15), (s)he is also considered at risk, without the other points.

\section{Procedure}

Data collection. The researcher collected the data in the course of two years, during the infants' routine pediatric appointments or through interviews with the parents. Thus, the assessments were longitudinal, guaranteeing the application of each of the CDRI ranges at least once. The families who accepted to participate in the study were recruited through the health professionals from the services where they were attended. Besides the parents' report, the researcher's observations of the parents-infant interaction were also taken into account. The CDRI was applied before the M-CHAT, that is, the study was blinded for the child's detection by means of the M-CHAT or not.

Data analysis. After the application of the tools, the children were divided in two groups: the control group (GC) included the infants who were not considered at risk based on the M-CHAT, and the group with signs of ASD (GT) included those infants considered at risk based on the same tool. The data were analyzed through a descriptive statistical research that compared the results of the GC and GT (on the CDRI and M-CHAT), as well as the individual results on the CDRI for GT children, so as to verify the tool's possible contribution to detect early signs of autism. Then, a clinical vignette is discussed, using the psychoanalytical theoretical framework, to demonstrate how the CDRI contributed 
to understand the family dynamics and can facilitate the conversation with parents about child development. The vignette was selected because it was the only case in the research in which the CDRI detected child suffering without the caregivers demonstrating any previous concern. Thus, it is discussed how the CDRI can facilitate the construction of forwarding for clinical care in a more favorable phase for child development. To investigate whether the CDRI axes could contribute to enhance the understanding of autism, the data were analyzed based on two non-parametric statistical tests: Kruskal-Wallis and Mann-Whitney. Due to the imbalanced number of individuals between the groups $(\mathrm{GC}=36$ and $\mathrm{GT}=7), \mathrm{GC}$ was randomly divided in five groups, which were mutually compared in turn. For all the analyses, statistical significance was set at 5\%.

\section{Ethical Considerations}

The research project is part of a larger project that received approval from the Ethics Committee for Research Involving Human Beings of the Instituto de Psicologia at the Universidade de São Paulo, under Protocol no. 2008.056. The infants identified as at developmental risk were forwarded for treatment at public network services that offer relational care to parents and infants.

\section{Results}

To associate the results obtained through the application of the CDRI with those of the M-CHAT, the total number of absent indicators each of the 43 children assessed obtained on the CDRI was determined. Figure 1 displays the frequencies of absent CDRI for the infants from the GC and GT.

The infants considered at risk for autism according to the M-CHAT were concentrated to the right on Figure 1, with a larger number of absent indicators on the CDRI. Among the children in the GC, $39 \%$ obtained two or more absent items, the criterion to be considered as at developmental risk. As a comparative parameter, all children in the GT had at least three absent items on the CDRI. The median number of absent indicators in the GC is 1, against 9 in the GT. This result indicates that the children considered at risk of autism on the M-CHAT also displayed early signs of developmental problems or mental risk on the CDRI. In the investigation of the association between the CDRI and M-CHAT results, the total number of absent indicators in infants from the GT was compared with the M-CHAT score (Figure 2).

Although the sample is insufficient to affirm the possibility of a linear correlation between the instruments, it can be observed in Figure 2 that, the higher the M-CHAT score, the larger the number of absent indicators on the CDRI. Hence, the exploratory analysis of these results demonstrates that, in the context of this research, the infants considered at risk of autism on the M-CHAT also displayed signs of mental

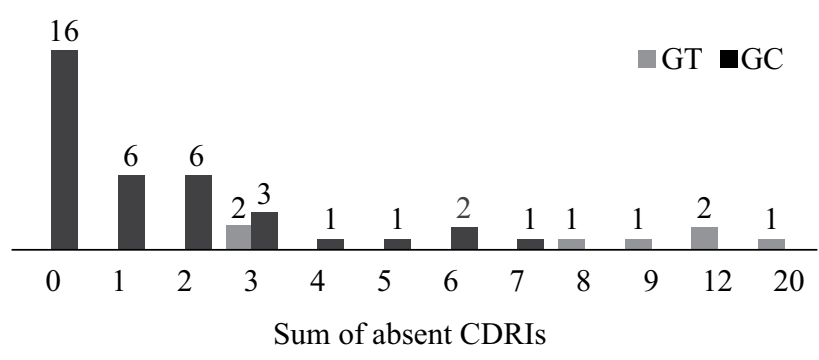

Figure 1. Frequency of indicators absent in infants with and without signs of ASD (total $=43$ infants).

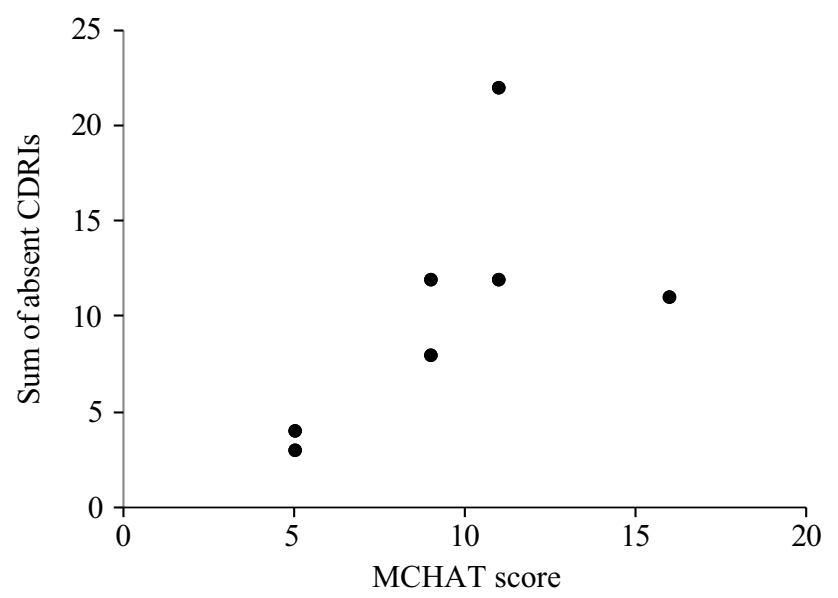

Figure 2. Dispersion diagram of sum of absent CDRIs and M-CHAT score in GT (total $=7$ infants).

suffering on the CDRI. This information suggests that the assessment of the mental aspects according to the CDRI seems to be sensitive to the child's degree of suffering.

The CDRI should not be considered a specific instrument to detect signs of autism in infants, which would reduce its value as a useful tool in the public health context. Autism is one of the risks the CDRI detects without any diagnostic specificity, which enriches the value of the instrument. In this perspective, as the CDRI was constructed based on four theoretical axes that relate to the constitution process of the subjects in their relation with their caregivers, it is relevant to investigate whether they can contribute to further the understanding of autism. Therefore, the results of the children in the GT were compared (Figure 3).

The data in Figure 3 demonstrated that none of the four axes was predominant among the children in the GT, that is, it cannot be affirmed that the early signs the children manifest are related to a specific matter. Three infants did not present any sign of risk on the subject assumption axis but, in one child, these were exactly the indicators that showed to be most problematic; two infants revealed more CDRIs absent on the alternate presence/absence axis, while two others showed a predominance of absent indicators on the paternal function axis.

Four children from the GT had at least one absent indicator on the subject assumption axis, corresponding to $57 \%$ of the sample in that group. In the GC on the other hand, 


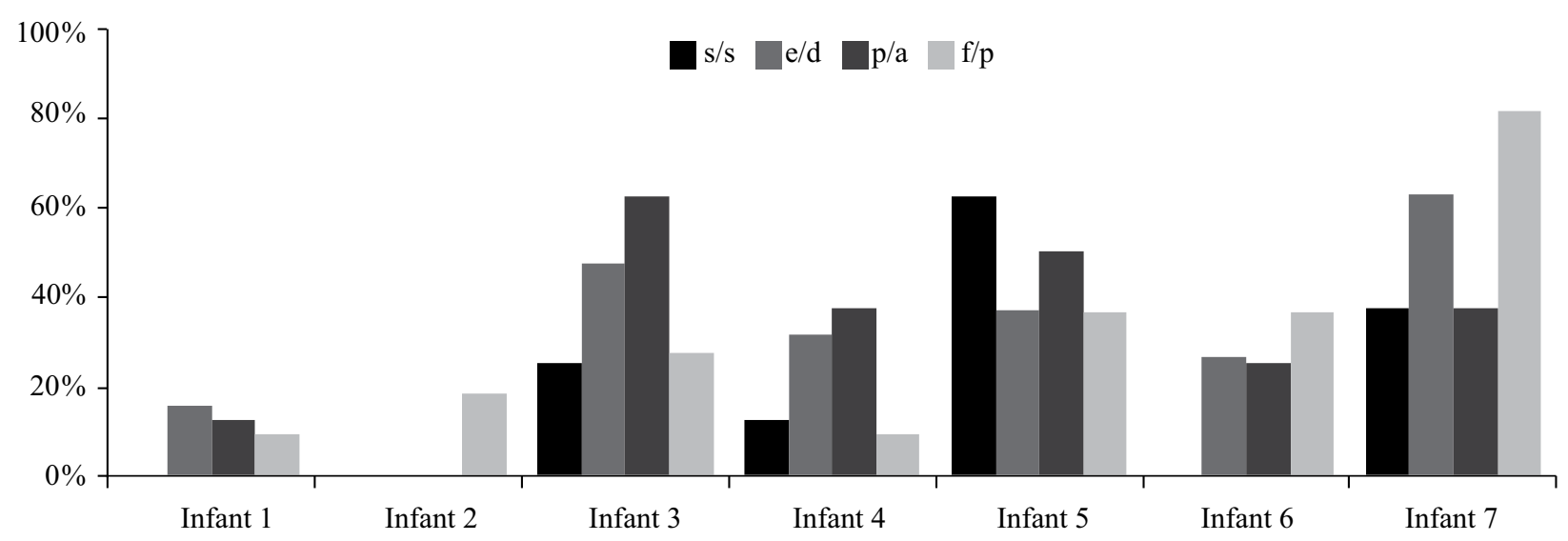

Figure 3. Percentage of Indicators absent per Axis in infants from GT.

five out of 36 children showed at least one absent CDRI on that axis, corresponding to $13 \%$ of the sample. When comparing the results, a 44-percent difference between the groups is found on the subject assumption axis. The same intergroup comparison for the other axes resulted in a 38-percent difference on the establishment of demand axis, 66-percent for the alternate presence/absence axis and 59-percent for the paternal function axis. To compare the results of the GC and the GT for the four CDRI axes, given the unbalanced sample, the GC was randomly divided in five groups and the Kruskal-Wallis test suggested no differences between these groups on any of the four axes at 5\%. When the GT was included in the comparison, however, the test result permitted the identification of differences at $5 \%$ on the ED, PA and FP axes among the groups. The SS axis did not show significant differences. This seems to show that the GT was responsible for the difference observed during the test. To confirm the result, the GT and GC subgroups were compared, one by one, using Mann-Whitney's test, confirming the first test applied. The ED axis showed 5\% differences in four of the comparisons ( $p$ between .007 and .017) and a marginal difference $(p=.053)$ in one of them. The PA axis showed differences at $5 \%$ in all comparisons ( $p$ - values between .004 and .017). On the FP axis, then, differences were observed in four comparisons ( $p$ - values between .002 and .017) and one of them showed no differences $(p=.097)$. In view of the first test result, it seems reasonable to consider that there are observable differences between children with and without early signs of autism on the ED, PA and FP axes and that there are no evidences of differences between them on the SS axis. It is further verified that the PA axis showed greater robustness in the differences, according to the descriptive analysis as well as the statistical test, which can arouse suspicions on whether this is the axis that most distinguished between children with and without early signs of autism. The results indicated that, as a whole, the CDRI, and maintaining is diagnostic non-specificity, is capable of detecting infants with early signs of autism. Next, a clinical vignette is presented that clarifies how the CDRI helped to understand the dynamics of a family.

\section{Clinical Vignette: Julia}

Julia (alias) was assessed by means of the CDRI protocol in the course of one and a half years during routine pediatric consultations. Hence, the indicators were applied through what the mother told the physician and through the observations made during the consultation about how the infant and her mother interacted in that context. The CDRI for the first two ranges indicated no reason for concern regarding Julia's development, although she was low-weight and the mother demonstrated vulnerability and concern with the fact that her husband had lost his job when their daughter was born. When the infant was 11 months older, the application of the third range showed three absent indicators. During the pediatric consultation, it could be observed that Julia did not try to make contact with her mother and that, even when the mother called her, she continued playing with her shoe without even looking at her. In addition, Julia walked across the room, moved everything she saw without hesitating and did not demonstrate fear or estrangement when her mother left the doctor's office to pick up a document from the reception desk, leaving her with the pediatrician and the researcher. These observations suggest a difficulty in the mother-infant interaction. In a discussion with the pediatrician and the research group, the need to follow Julia and her mother more closely was perceived. They did not attend the pediatric consultations during eight months though and the researcher was unable to contact them again, as the telephone number had changed. Julia was 20 months old when she was assessed again. The two final ranges of the CDRI and the M-CHAT were applied. Although the third range had already been applied, the decision was made to reapply it, even previously, to assess the girl's developmental evolution. While the researcher was talking to the mother about Julia's development, the child remained quiet in a corner of the room, seemed passive and indifferent to what was happening. The researcher offered her a toy but Julia did not take it. The mother seemed uncomfortable because of the girl's lack of response and offered the girl a toothpick but Julia did not react; the mother insisted and, during the fourth 
attempt, introduced the toothpick in the child's mouth. Julia stayed still, immobile, with the toothpick between her teeth. On that day, a series of misses made the situation border on the unbearable: the mother clearly felt weakened because of her daughter's difficulties but did not express them. On the opposite, she was repeating at all times that Julia was excellent and, thus, did not offer space to discuss the anguish and difficulties. And the infant was left adrift, without being able to make significant contact in the situation. The M-CHAT completed by the mother did not indicate risk for autism, but the CDRI signaled a situation of suffering that should be heard. At that time, however, talking to the mother about the need for forwarding to intervene in the parent-infant relationship was impossible, as she had not formulated a demand. Therefore, the researcher proposed a return conversation for the father to participate as well and for the mother to have time to get in touch with the emotions aroused during the final conversation. The mother attended the return conversation with Julia but the father was unable to. The researcher started the dialogue by asking the mother what it was like for her to participate in the research and how she perceived her daughter, but the mother did not accept any of these invitations to talk freely; she said that everything was fine. In view of her reaction, the researcher used the instruments as facilitators to transmit the observations reached during more than one year of monitoring to the mother. After acknowledging the potentials and the resources she and her child presented, the difficulties and misses could be named. Going through the indicators allowed the mother to discuss the difficulty she felt during Julia's first months of life. She reported that she not only could not bear her daughter's crying, but also had to deal with her husband's anguish with regard to the baby, given that she was low weight and that her paternal grandfather had died when she was born. Despite naming the anguish and misses, the mother insisted on saying that the difficulties had passed and that everything was fine now. Thus, the researcher explained that, although the initial difficulties had been soothed, she and her daughter could be followed at a service that offered care to parents and infants. The mother, with a more serene face, answered: “[...] I want to! I'll go! Going won't hurt anyone, right? And, you know, I've even considered that my daughter could be autistic [...]".

\section{Discussion}

Based on each of the 43 children's result on the CDRI, it was verified that all infants considered at risk for autism on the M-CHAT were also detected through the CDRI. Seventy-two percent of the children in the GT obtained between 8 and 20 absent indicators - the largest numbers in the sampling universe. In addition, the comparison between the results obtained on the CDRI and the M-CHAT suggest a trend in which, the higher the score on the M-CHAT, the larger the number of absent indicators on the CDRI. These results demonstrate that, although the CDRI is a non-specific instrument for diagnostic purposes, it can detect infants who are developing autism. Also, the tool seemed to be sensitive to the child's degree of suffering. Nevertheless, although the Multicenter Research (Kupfer et al., 2009) and Lerner's research (2011) highlighted indicators or factors (associated indicators) with statistically significant associations to predict risk, this study highlights the capacity of the CDRI as a whole to detect early signs of autism. This distinction is important because it values the set of 31 indicators to read the infant's development and the interaction established between infant and caregivers.

In that sense, Julia's clinical vignette was fundamental not only to detect signs of suffering in the bond between parents and infants, but to facilitate the conversation with the pediatrician and the child's mother. Lebovici (1987) had also alerted to the fact that tools systemize clinical impressions and can serve as a communication medium between the professional responsible for the assessment and the children's parents.

The exploratory study that compared the results of the CDRI with the M-CHAT replicated literature data about the M-CHAT being more effective to detect high-risk infants risco (Chlebowski et al., 2013; Scarpa et al., 2013; Snow \& Lecavalier, 2008). Julia's case demonstrates that she was not considered at risk of autism according to the M-CHAT, despite presenting significant developmental problems detected by the CDRI and which justified the forwarding for intervention in the parents-infant relationship. In addition, as the CDRI is a continuing assessment instrument, it permits the detection of signs of mental suffering before the age of 18 months, contributing to the possibility to offer the intervention even earlier.

These results introduced the discussion about the general trend demonstrated by a group and the singularity of each case. In other words, no matter the regularity typical children display in their development, each child develops in a particular way. Similarly, despite the existence of criteria that permit the construction of the autism diagnosis, the signs and symptoms are not expressed in the same way in different children.

As to the subject assumption axis not having demonstrated significance to distinguish GT and GC children, studies reveal the fact that the parents of children who became autistic invested libidinally in their infants during the first months of life (Cassel, 2011; Cohen et al., 2013; Laznik, 1995/2011); after a long period without the children's response, however, the parents reduced their calls. Lerner (2011) found that the trend towards detachment expressed by infants who turned into autistic children does not seem to cause a reaction of distancing in the parents during the first 12 months of life and that it is only after the children's first year of life that the parents start to suffering the most noteworthy effects of the condition the children express. Similarly, Cassel (2011) concluded that, in the first six months of life, the mothers called their infants but that, 
in the second term, a change was found in the frequency of calls due to the infant's lack of response. The studies by Spitz (1965/2004) recovered the importance of caregivers supposing that the small infant contains a subject. When that does not happen, there is a great change that the interaction will be impaired, as well as the child development. Hence, in a dialogue between general and particular trends, the intent is to discuss the impossibility of generalizing the fact that the children who became autistic did so because their parents did not consider them as subjects. It cannot be affirmed either, however, that if behaviors related to the Subject Assumption axis are absent, this will not entail consequences for the children's development.

The discussion about the suspicion that the alternate presence/absence axis is the most distinctive between GT and GC children remains a hypothesis according to the data observed in this study. Nevertheless, the articulation between this axis and information offered in the literature suggests that deepening the research in terms of the waiting, the separation and loss, can be useful to assess infants who are developing autism. In the studies by Tustin (1972/1990), the infants' perception of an early separation experience is highlighted as a crucial factor for autism, that is, they have contact with the distinction I-other at a time when he cannot signify that experience. Tustin found echoes of this observation in the writings of Mahler and Winnicott, who considered the feeling of early loss as a starting point for childhood autism.

The vignette presented demonstrates that the CDRI can be used as a reading operator that helps to understand the family dynamics and can guide punctual interventions during the assessment. In the case of infants who are suspected to be at risk of autism, despite affirming the neurodevelopmental nature of the disease (Fernell et al., 2013; Rutter, 2011; Zanon et al., 2014), the environment and the interaction the infants establish with their caregivers play a fundamental role in this process, as indicated in different psychoanalytical studies (Alvarez, 1994; Freud, 1926/1996; Klein, 1952/1991; Lebovici, 1987; Mahler, 1965/1982; Spitz, 1965/2004; Winnicott, 1967/1975). Figueiredo (2012) affirms that the care agent should practice his function as implied presence, which means being committed and active. The authors describes three modalities of implied presence the caregiver can adopt at different time: sustaining and containing (contains the holding function Winnicott proposed in 1960, and the containing function Bion proposed in 1970, which guarantee the experiences of continuity and transformation), recognizing (being capable of paying attention and recognizing the characteristic singularity of the care object, taking the subject's own image back to him) and challenging and complaining (referring to the distinguished other, marked by difference and incompleteness). Here, the other who challenges and complains functions as an agent of confrontation and limitation, putting the subject in contact with the existential facts: death, finiteness, alterity and the law.
The functions Figueiredo highlights can be extended to the professional who proposes the assessments by means of the CDRI protocol. Meaning or new meanings can be attributed to the infant's actions and to the established interaction patterns. In addition, particularly in those cases in which there are problems in the parents-infant relationship, the CDRI ended up functioning as the caregivers' complainant (Alvarez, 1994; Figueiredo, 2012) since, at the same time as it summoned them to look at their infants, it also offered them limits in the sense of contours, alterity and finiteness. Hence, if the researcher adopts the posture of a care agent when applying the CDRI, a potential space can be established (Winnicott, 1967/1975) that will facilitate important appointments and transformations for the parents-infant interaction and, therefore, for child development.

These study results indicated that the CDRI protocol detects early signs of developmental problems in children who are developing autism. This does not mean that it should be considered a specific screening tool for autism in infants of up to 18 months old. Making this distinction is important, as the CDRI can contribute to consider the subjectivity of each infant/family and to detect different symptomatic manifestations of the spectrum. In addition, as a continuing assessment instrument, applied in the course of one and a half years, it admits different moments to observe the emergence and evolution of the early signs of suffering. That contributes to the possibility to offer the clinical intervention at increasingly timely moments, without the need to wait until the age of 18 months. Deepening or updating the knowledge on this tool can contribute towards its more precise use and interpretation of its results, with a view to promoting health instead of imprisoning subjects in diagnostic predictions or alarming the parents about possible difficulties involving their small children. Based on this study, it can be affirmed that the CDRI can support the understanding of the family dynamics and can facilitate the conversations with the children's parents or with the care network professionals. Also, the protocol allows the clinician to interpret the meaning the absence of a certain clinical indicator can have in the context of each family. Further research is suggested to verify the possibility of using this tool as an intervention method for mental health promotion purposes, and also of checking its sensitivity to autism, given that the sample size does not permit generalizations.

\section{References}

Alvarez, A. (1994). Companhia viva psicoterapia psicanalitica com crianças autistas, borderline, carentes e maltratadas (M. A. V. Veronese, Trans.). Porto Alegre, RS: Artes Médicas.

American Psychiatric Association. (2014). Manual diagnóstico e estatístico de transtornos mentais: DSM-5 (M. I. C. Nascimento, P. H. Machado, R. M. Garcez, R. Pizzato, \& S. M. M. Rosa, Trans., 5th ed.). Porto Alegre, RS: Artmed. 
Campana, N. T. C., \& Lerner, R. (2014). Trocas alimentares entre bebês irmãos de autistas e suas mães: Risco ou recurso? Revista Latinoamericana de Psicopatologia Fundamental, 17(2), 191-203. doi:10.1590/1984-0381v17n2a04

Cassel, R. (2011). Dynamique, synchronie, réciprocité et mamanais dans les interactions des bébés autistes à travers les films familiaux (Doctoral dissertation, Université Pierre et Marie Curie, Paris, France). Retrieved from http://tel.archives-ouvertes.fr/docs/00/64/66/08/ PDF/thA_se_CSG_avec_plos_one_pdf

Centers for Disease Control and Prevention. (2014). Prevalence of autism spectrum disorder among children aged 8 years - autism and developmental disabilities monitoring network, 11 sites, United States, 2010. Morbidity and Mortality Weekly Report Surveillance Summaries, 63(2),1-21.

Chlebowski, C., Robins, D. L., Barton, M. L., \& Fein, D. (2013). Large-scale use of the modified checklist for autism in low-risk toddlers. Pediatrics Online, 131(4), e1121-1127. doi:10.1542/peds.2012-1525

Cohen, D., Cassel, R., Saint-Georges, C., Mahdhaoui, A., Laznik, M.-C., Apicella, F.,... Chetouani, M. (2013). Do parentese prosody and fathers' involvement in interacting facilitate social interaction in infants who later develop autism? PlosOne, 8(5), e61042. doi:10.1371/journal.pone.0061402

Eaves, L. C., Wingert, H., \& Ho, H. H. (2006). Screening for autism: Agreement with diagnosis. Autism, 3(10), 229-242.

Figueiredo, L. C. (2012). As diversas faces do cuidar: Novos ensaios de psicanálise contemporânea (2nd ed.). São Paulo, SP: Escuta.

Freud, S. (1996). Inibições, sintomas e ansiedades (J. O. A. Abreu \& C. M. Oiticica, Trans.). In Edição Standard Brasileira das obras completas de Sigmund Freud (Vol. 20, pp. 81-171). Rio de Janeiro, RJ: Imago. (Original work published in 1926)

Fernell, E., Eriksson, M. A., \& Gillberg, C. (2013). Early diagnosis of autism and impact on prognosis: A narrative review. Clinical Epidemiology, 5, 33-43. doi:10.2147/CLEP.S41714

Klein, M. (1991). Algumas conclusões teóricas relativas à vida emocional do bebê (B. Mandelbaum, M. E. S. Britto, O. B. Salles, M. T. Godoy, V. Starzynski, \& W. M. Dantas,Trans.). In Inveja e gratidão e outros trabalhos 1946-1963 (pp.85-118). Rio de Janeiro, RJ: Imago. (Original work published in 1952)

Kupfer, M. C. M., Jerusalinsky, A. N., Bernardino, L. M. F.,Wanderley, D., Rocha, P. S. B., Molina, S. E.,... Lerner, R. (2009). Valor preditivo de indicadores clínicos de risco para o desenvolvimento infantil: Um estudo a partir da teoria psicanalítica. Latin American Journal of Fundamental Psychopathology Online, $6(1), 48-68$.
Kupfer, M. C. M., Jerusalinsky, A. N., Bernardino, L. M. F., Wanderley, D., Rocha, P. S. B., Molina, S. E.,... Lerner, R. (2010). Predictive value of clinical risk indicators in child development: Final results of a study based on psychoanalytic theory. Revista Latinoamericana de Psicopatologia Fundamental, 13(1), 31-52. doi: 10.1590/S1415-47142010000100003

Kupfer, M. C. M., Bernardino, L. M. F., Mariotto, R. M. M., Pesaro, M. E., Lajonquiêre, L., Voltolini, R., \& Machado, A. M. (2013). Metodologia IRDI: Uma ação de prevenção na primeira infância. In M. C. F. Kupfer, L. M. F. Bernardino, \& R. M. M. Mariotto (Orgs.), Psicanálise e ações de prevenção na primeira infância (pp.131-145). São Paulo, SP: Escuta/FAPESP.

Laznik, M.-C. (2011). Rumo à fala: Três crianças autistas em psicanálise (P. Abreu, Trans.). Rio de Janeiro, RJ: Cia de Freud. (Original work published in 1995)

Lebovici, S. (1987). O bebê, a mãe e o psicanalista (C. E. Reis, Trans.). Porto Alegre, RS: Artes Médicas.

Lerner, R. (2011). Indicadores clínicos de risco para $o$ desenvolvimento infantil - IRDI: Verificação da capacidade discriminativa entre autismo, retardo mental $e$ normalidade (Unpublished associate professorship thesis).Universidade de São Paulo, São Paulo, SP.

Lerner, R., \& Kupfer, M. C. M. (Orgs.). (2008). Psicanálise com crianças: Clínica e pesquisa. São Paulo, SP: Escuta.

Lerner, R., Paolo, A. F., Campana, N. T. C., Morais, A. S., Tocchio, A. B., \& Silva, R. R. F. (2013a). A psicologia na articulação entre os âmbitos coletivo e psíquico: Construção de uma política pública em saúde de cuidado com o desenvolvimento. Psicologia: Ciência e Profissão, 33(No. Esp.), 100-111.

Lerner, R., Paolo, A. F., Campana, N. T. C., Morais, A. S., Tocchio, A. B., \& Silva, R. R. F. (2013b). Uma contribuição da psicanálise para a saúde coletiva: Protocolo de indicadores clínicos de risco para o desenvolvimento infantil. Revista Latino-Americana de Psicanálise, 1(1), 226-237.

Mahler, M. (1982). A interação mãe-filho durante a separação-individuação (H. M. Souza, Trans.). In M. Mahler, O processo de separação-individuação (pp. 35-45). Porto Alegre, RS: Artes Médicas. (Original work published in 1965)

Mariotto, R. M. M. (2009). Cuidar, educar e prevenir: As funções da creche na subjetivação de bebês. São Paulo, SP: Escuta.

Pesaro, M. E. (2010). Alcance e limites teórico-metodológicos da pesquisa multicêntrica de indicadores clínicos de risco para o desenvolvimento infantil (Unpublished doctoral dissertation). Universidade de São Paulo, São Paulo, SP.

Pinto-Martin, J. A., Young, L. M., Mandell, D. S., Poghosyan, L., Giarelli, E., \& Levy, S. E. (2008). Screening strategies for autism spectrum disorders in pediatric primary care. Journal of Developmental and Behavioral Pediatrics, 29(5), 345-350. doi:10.1097/DBP.0b013e31818914cf 
Rutter, M. L. (2011). Progress in understanding autism: 20072010. Journal of Autism and Developmental Disorders, 41(4), 395-404. doi:10.1007/s10803-011-1184-2

Scarpa, A., Reyes, N. M., Patriquin, M. A., Lorenzi, J., Hassenfeldt, T. A., Desai, V. J., \& Kerkering, K. W. (2013). The modified checklist for autism in toddlers: Reliability in a diverse rural American sample. Journal of Autism and Developmental Disorders, 43(10), 2269-2279. doi:10.1007/s10803-013-1779-x

Snow, A. V., \& Lecavalier, L. (2008). Sensitivity and specificity of the modified checklist for autism in toddlers and the social communication questionnaire in preschoolers suspected of having pervasive developmental disorders. Autism, 12(6), 627-644. doi:10.1177/1362361308097116

Spitz, R. (2004). O primeiro ano de vida (E. M. B. Rocha, Trans., 3rd ed.). São Paulo, SP: Martins Fontes. (Original work published in 1965)

Tustin, F.(1990). Barreiras autistas em pacientes neuróticos (M. C. Monteiro, Trans.). Porto Alegre, RS: Artes Médicas. (Original work published in 1972)

Winnicott, D. W. (1975). O brincar e a realidade (J. L. Camargo, Trans.). Rio de Janeiro, RJ: Imago. (Original work published in 1967)

Zanon, R. B., Backes, B., \& Bosa, C. A. (2014). Identificação dos primeiros sintomas do autismo pelos pais. Psicologia: Teoria e Pesquisa, 30(1), 25-33. doi:10.1590/S0102-37722014000100004

Nathalia Teixeira Caldas Campana holds a M.Sc. in School and Human Development Psychology from the Universidade de São Paulo.

Rogério Lerner is an Associate Professor at the Instituto de Psicologia of the Universidade de São Paulo.

Vinicius Frayze David holds a M.Sc. in Psychology from Universidade de São Paulo.

Received: June 8, 2014

1st Revision: Nov. 1, 2014

Approved: Nov. 24, 2014

How to cite this article:

Campana, N. T. C., Lerner, R., \& David,V. F. (2015). CDRI as an instrument to evaluate infants with developmental problems associated with autism. Paidéia (Ribeirão Preto), 25(60), 85-93. doi: 10.1590/1982-43272560201511 